\title{
18
}

\section{How to publish a peer-reviewed research paper from integrative landscape research}

Gunther Tress ${ }^{\#}$, Bärbel Tress ${ }^{\#}$ and Gary Fry ${ }^{\# \#}$

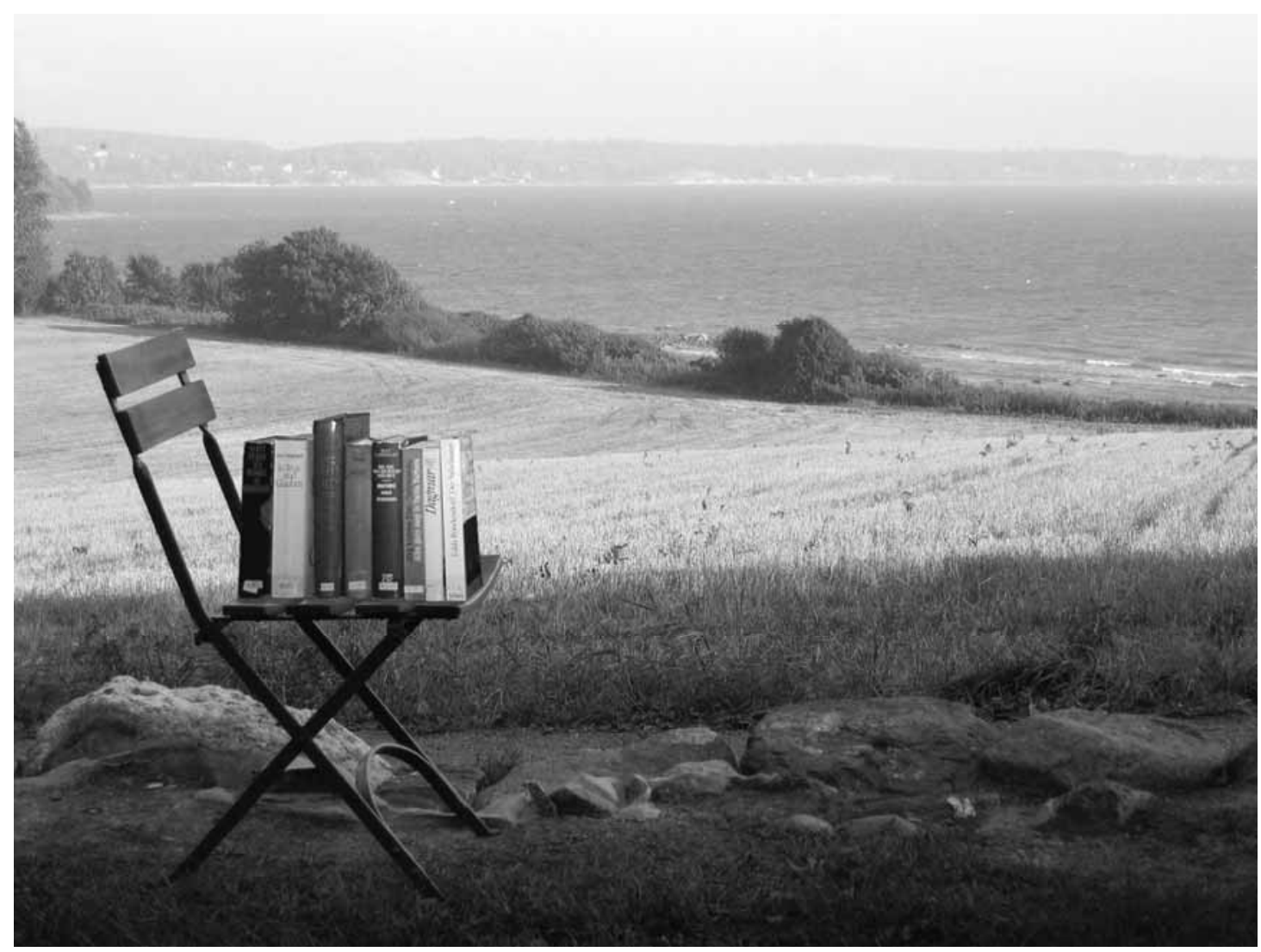

\section{Abstract}

Publishing is an important aspect of communication in the sciences and contributes to its progress. Researchers involved in integrative landscape research perceive it to be more difficult to publish integrative studies than disciplinary studies. Therefore, the objective of this chapter is to provide guidelines for writing and publishing a research paper in a peer-reviewed journal or as a chapter in a book series. The chapter focuses on young researchers working on integrative landscape topics. The chapter is divided into two sections: the preparation of a research paper and the editorial and peer-review process. In the first part, a roadmap guides the researcher through each step involved in paper preparation and writing. The second part discusses the roles of the editor,

\footnotetext{
${ }^{\#}$ Land Use Planning Group, Department of Environmental Sciences, Wageningen University, Generaal Foulkesweg 13, 6703 BJ Wageningen, The Netherlands. E-mail: tress@tress.cc, http://www.tress.cc

\# Institute of Landscape Planning, Norwegian University of Life Sciences, P.O. Box 5029, N-1432 Ås, Norway. E-mail: gary.fry@umb.no
} 
referees and publisher and describes the editorial and peer-review process. The chapter concludes with guidelines for successful publication, from preparation to acceptance.

Keywords: publishing; manuscript preparation; manuscript structure; review criteria; editorial process; interdisciplinary; transdisciplinary

\section{Introduction}

The aim of this chapter is to provide guidelines for writing and publishing a research paper in a peer-reviewed journal or book. The chapter focuses on young researchers and $\mathrm{PhD}$ students, who are less experienced with the writing, peer-review and publishing process. Special attention is given to problems and challenges related to publishing from integrative (i.e. interdisciplinary and transdisciplinary) landscape research. Additionally, the chapter provides a brief introduction to the editorial and review process of a peer-reviewed research paper to give authors an overview of the steps taken prior to publication. Finally, the chapter closes with guidelines and recommendations for successful preparation and submission of a research paper.

\section{Why publish?}

While immersed in integrative research, young researchers struggle with challenges of integration, as described by Fry (2001), Spanner (2001), Bruce et al. (2004), Jakobsen et al. (2004), Fry et al. (2005) and Tress et al. (2005; 2005). They must cope with different academic traditions, different methodologies, distances separating research teams, difficulties in leadership and personal chemistry, lack of common terminology, unsuitable organizational infrastructure and the additional time needed for integration. Frequently, researchers feel compelled to devote more energy, effort and resources to meeting these challenges, realizing integration, and solving 'real-world' problems than to publishing from integrative research. Researchers may even question the need to publish, seeing it as an old-fashioned habit of traditional disciplinary research. Rest assured, it is not. We see four main reasons why researchers from integrative projects should publish:

1. Publishing is an important part of research communication! The foremost reason for publishing research results is to communicate the findings to other people. Within academia, publishing fulfils the aim of communicating research results to other researchers and potential users.

2. Publishing contributes to scientific progress. Publishing assures that new findings get known as widely as possible among a group of researchers dealing with a certain topic. Other researchers benefit from the new findings and build upon them in their own research.

3. Publications are academic currency. Researchers are evaluated according to the number of publications they have produced. Funds for research projects and travel grants are allocated based on publication records. Career promotion is also dependent on publishing.

4. Publishing is a quality control. Once research results are published they are disclosed to the academic community and can be evaluated and judged by other experts. This helps to test the validity and reliability of research results. This process starts immediately after submitting a paper to a peer-reviewed journal or a book. At this point experts in the field (the peers) review the submission's merit for publication. Thus, once published, peer-reviewed publications - and thereby their authors - have obtained a certain quality label. 


\section{Publishing integrative landscape research}

Publishing integrative landscape research fulfils the same important functions as for other types of research: communication, scientific progress, career development and quality control. However, recent research on publishing performance and publication patterns of integrative landscape researchers has shown that they perceive it to be more difficult to publish from integrative research (Tress, Tress and Fry 2005) than from discrete disciplines. Analysis of editorial policies of peer-reviewed journals in the field of landscape research, however, reveals that editors welcome integrative papers (Fry, Tress and Tress 2004) and assert that they do not get enough integrative papers submitted. Therefore, editorial policies cannot account for researchers' reluctance to publish. The perception of difficulty can be attributed to the extra time needed to jointly compile and write up integrative results, reconcile conceptual differences and terminology across research fields, as well as to the lack of experience with the writing and publishing process in general.

\section{Target audience and publication types}

Before starting to write a paper, researchers involved in integrative research have to specify the target audience and type of publication. The target audience can be very heterogeneous because research results might be communicated to researchers from a variety of backgrounds and levels including research managers, policymakers, stakeholders and other end-users, as well as the general public. Defining the target audience also determines the type of publication.

Several types of publications reach the academic audience: books, journal papers, theses, proceedings, reports and online publications. These types receive different degrees of respect in different academic circles. Peer-reviewed journal publications have the highest ranking because of their peer-review system. They are also the most influential in terms of scientific impact and career advancement. Within these media different types of papers can be produced: research papers, review papers, and theory and discussion papers.

Research papers are the most common type of paper and include original/primary research done by the authors. Review papers present a state-of-the-art overview of a specific and relevant topic within a research field. A review paper does not build on one's own research activities but structures the existing knowledge in this field by compiling the most relevant literature on it. A theory or discussion paper either presents new theory developed by the authors or discusses an important and relevant topic in a research field based on existing literature and/or the author's own ideas.

In this chapter, we focus on the communication of integrative research results to an academic audience comprising an interdisciplinary readership by preparing peerreviewed research papers for journals or books.

\section{Preparing a research paper}

\section{Roadmap for a research paper}

Before starting on a research paper it is helpful to think about following a roadmap for the writing process. Once an idea for a research paper has been developed, the following steps need to be taken:

1. The research on which the paper will report must be completed. Preliminary results are less suitable for a full research paper and will most likely not be accepted by a journal or a book editor.

2. Select a journal or book where the manuscript will be published. 
3. Determine the paper's authorship: identify the first author and the role that coauthors will play.

4. Define clear objectives for the research paper.

5. Select the paper's working title.

6. Organize the paper's main body into sections: introduction, methods, results, discussion and conclusion.

7. Write each paper section. Keep the objectives of the paper in mind when writing all sections.

8. If applicable, write an acknowledgment section to give credit to other researchers for their help or to refer to research grants.

9. Include all references used in the paper in the reference section (can be done in tandem with the writing of the other manuscript sections).

10. Choose a precise and informative title as well as keywords that will help identify the paper in database searches.

11. Prepare an abstract that summarizes the objectives, methods, results and conclusions sections and gives the reader enough insight to understand what they can expect from reading the paper.

12. Format the manuscript according to the guidelines of the given journal or book series. Check the quality and style of language.

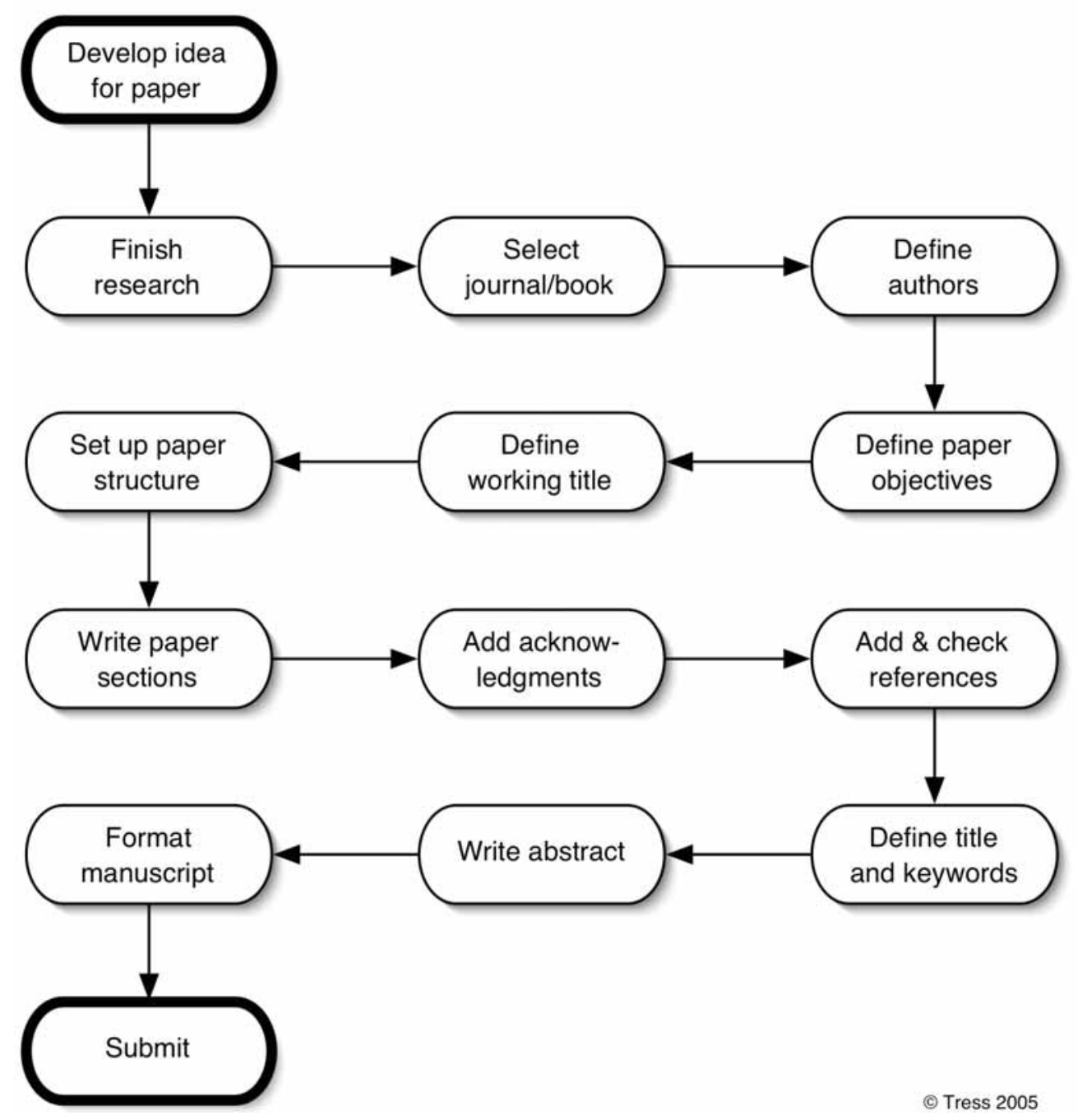

Figure 1. Roadmap for an integrative research paper 
As the bulk of the writing process, step 7 is very important, but each of the other steps is important as well. The twelve steps are described below with special attention to the individual sections to be written within step 7. For more discussion of paper writing, refer to Provost (1985), Day (1998), CBE (2002), Luey (2002), Rothwell (2002), Booth (2003), and Gustavii (2003). Figure 1 presents the roadmap for an integrative research paper.

\section{Authorship}

Determining authorship of a research paper is an important step and needs to be done before the writing process starts. Decide whether there is only one author on a paper or an author collective. In a single-author paper the whole writing process is left to the individual author. It is therefore most likely that this author has done the work reported in the paper. In an author collective, usually all authors contribute significantly to the research and the writing. If other people have contributed to the research but have agreed not to be co-authors of the paper, their contribution needs to be acknowledged in the acknowledgment section.

Papers resulting from integrative landscape research are often multi-author papers because several researchers from different disciplines are involved in the research. In this case, the decision of who is the paper's first author and in which order other authors are listed is very important. As a general rule, first author is the one who has done most of the work related to the paper. Co-authors are those who have significantly contributed to the work reported in the paper or written parts of it. Their contribution could be data collecting, analysis, securing funding or other support needed to conduct the research.

The author listed first is considered to be the main contributor to the work and thus receives most of the credit. For multi-author papers in integrative landscape research it may not always be easy to determine one main author because all authors may have contributed equally. In this case authors might consider rotation of first authorship when several papers are to be written. Alternatively, authors can agree to prepare an author declaration that documents the equal contribution of all authors to a paper. We recommend listing only those people as authors on a paper who have had a role in developing the research material or were involved in the writing process.

For the PhD student, it is often the case that their supervisor is listed before the student on his/her first published paper as the supervisor has played a major role in developing the paper from the student's project. In a second paper, as the student becomes more advanced, the roles may change. A third paper may be a single-author paper by the $\mathrm{PhD}$ student.

\section{Manuscript structure and the IMRAD format}

Before starting the paper, we recommend outlining the main sections and all necessary sub-sections. This structure should reflect and support the objectives of the paper. For most research papers the IMRAD format is a helpful structure to follow (Day 1998). IMRAD stands for Introduction, Methods, Results And Discussion. Most research papers follow this format in one way or another. However, it is more common in natural-science papers than in papers from social sciences or humanities. It helps authors to organize the research they are reporting in the paper and it helps readers to orient themselves easily. Most journal editors leave the paper structure to their authors. We know, however, that for inexperienced writers the IMRAD format is a great help, assuring that all important aspects of a paper are reported systematically. 
Research papers serve other objectives than poetry, novels or fiction; the purpose of a research paper is to communicate research results. The scientific author is not expected to include surprising elements to entertain the reader or to demonstrate eloquence. We recommend the use of simple language, without fancy expressions or sophisticated style. The clearer and more logical a paper is structured, the better it serves its academic purpose. For integrative papers, a well-defined structure is essential because authors and readers may come from different academic/disciplinary backgrounds with various traditions and writing styles.

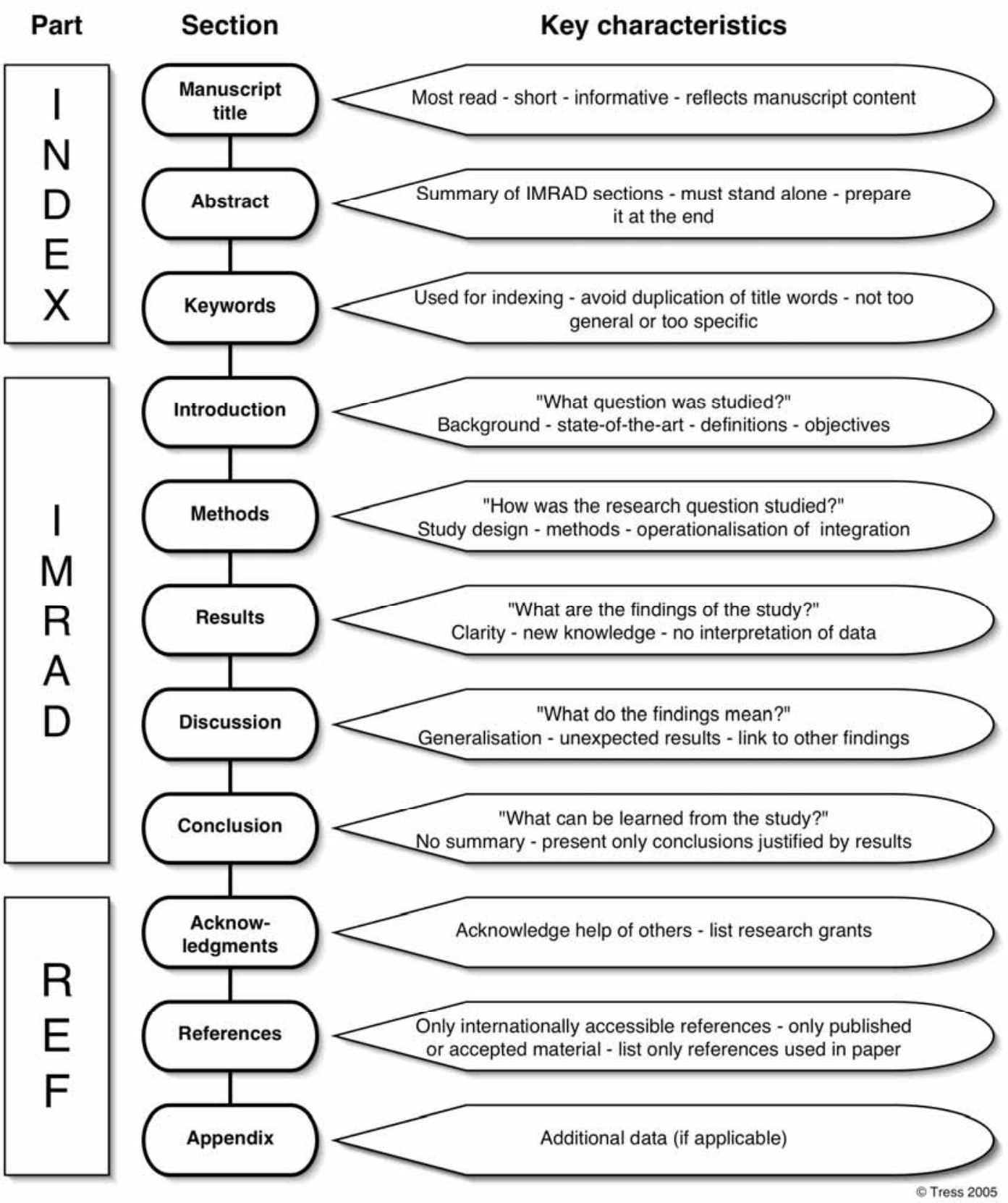

Figure 2. Manuscript structure and key characteristics of manuscript sections

Although the sections comprising the IMRAD format are the most important elements of the paper, the sections that immediately precede and follow the IMRAD sections are also necessary (see Figure 2). The INDEX contains manuscript title, abstract and keywords as well as author information and contact addresses. This 
information is used for indexing the manuscript and is often read outside of the context of the whole manuscript. The sections at the end of a manuscript comprise the REF section, including acknowledgment, references and appendix. Only the references section is obligatory; the two other appear only if appropriate. Figure 2 illustrates the research paper's organization into these three parts, the sections within them, and the key characteristics of each section. Brief descriptions of each section follow.

Preparing and writing a research paper is not a linear process where one starts with the title, followed by the abstract, the keywords, the introduction, the methods and so on. We recommend first defining the objectives of the paper and then writing the methods section.

\section{Manuscript title}

The title of a manuscript is very important. It is the part that is read most frequently. Most readers will first encounter a manuscript by reading the title. Whether readers access the paper and read it depends on whether the title gives enough information to attract their attention. As a consequence, the manuscript title needs careful preparation. When starting with the writing process of a paper it is good to have a working title. Once the paper is finished, a definitive title needs to be drafted to reflect fully its content. According to Day (1998), a good title includes the fewest possible words to describe adequately the content of a manuscript. A title should be understandable when read in isolation from the paper. Avoid abbreviations and jargon in the title and try to be as concise as possible. The title of a manuscript need not be a full grammatical sentence; therefore, articles ('a', 'the') can be left out (e.g. "Analysis of ...” instead of "The analysis of ...”).

\section{Manuscript abstract}

The abstract is a mini-version of the whole paper. This section informs the reader about the general content and determines the paper's relevance for the reader. An abstract is the second most frequently read part of a research paper. It needs to raise the reader's interest. It is written as one paragraph, normally not exceeding 250 words. Literature references are left out. The abstract should inform the reader about the objective of a paper, its context, the methods, the main results, the points of discussion and the chief conclusion. As a general rule, each manuscript section is summarized in approximately two to three sentences. Never present statements and conclusions in the abstract that are not included in the paper.

\section{Manuscript keywords}

Keywords are used to index the paper in the bibliometric databases and to help readers find papers within a certain subject field. For each paper, the author defines approximately five to seven keywords. It is not necessary to repeat keywords that are already included in the title because the title is also used for indexing in databases. Instead, keywords are used to give additional information. Keywords can also include short phrases, but in any case they should be neither too general nor too specific. Keywords like 'research' and 'landscape' are of no great help in publishing a paper on landscape research because too many other papers would fall under the same search criteria; similarly, keywords are not helpful when they are so specific that interested readers would be unlikely to use them in their search. We recommend that authors test their keywords by typing them into reference databases (such as Science Direct, 
Scirus, ISI, Current Contents and others) and seeing whether they achieve a satisfying search result.

\section{Introduction}

As a general rule, the introduction informs the reader about the subject reported in the paper. The introduction supplies the reader with sufficient information on the motivation for, and context of, the study to understand and evaluate the results presented in the manuscript. All relevant information should be included so that the reader does not need to read previously published studies to understand the manuscript. A state-of-the-art overview helps the reader to understand the international context and relevance of the study's results.

Open the introduction with the arguments for the importance of a specific topic and the scope of the problem. Then, review the literature not only to communicate the latest findings within the field but also to identify gaps that need additional research. Ideally, this research paper fills some of those gaps. It is highly important to state the objective of the paper in the introduction. A clear aim permits the reader to understand the research question to be answered. A paper without objectives is a major barrier in communication between authors and readers; readers are left wondering why the research was done and what is the key message of the paper.

All terms and concepts used in the paper should be briefly explained in the introduction. Integrative research papers benefit particularly from this clarification since authors from different academic disciplines use concepts that are probably wellknown within their peer group but not by the paper's broad readership. The introduction may also be used to state briefly the key methodological steps taken to reach the research objectives and introduce the structure of the paper.

\section{Methods}

The methods section of a paper is needed to inform the readers about the approach to the research question. This section explains the experimental design of the study and provides sufficient background information to help the reader understand, evaluate and potentially replicate the study. This section is set up chronologically, explaining the different methodological steps one after the other. In integrative landscape-research papers, attention should be given to two issues. First, the different methodologies applied in the study need explanation since the methodologies used by different disciplines might be unfamiliar to readers with other backgrounds. Common methodologies that the interdisciplinary research team has developed across disciplinary borders need special introduction. Second, the reader will be interested in the approach and realization of research integration. It is not enough simply to state that the study was integrative (Tress, Tress and Fry in press). The methods section should give insights into the methodological and conceptual steps that distinguish this study from a disciplinary or multidisciplinary one.

To be of any scientific merit, the methods must be clearly described. The way that methods lead to results must be understandable and reproducible, especially concerning methodological or experimental design. Papers get rejected when there are doubts about the methodology. The description of methods is equally important in the natural sciences, social sciences and humanities, whether approaches are quantitative or qualitative. Helpful criteria for describing the methodological quality of a study can be found in Van der Sanden and Meijman (2004). 


\section{Results}

This section informs the reader about a study's findings. Less experienced authors consider this section to be the most important one and focus more on the results than the methods or discussion. Yet, in a paper that communicates the whole research process, the results section represents only one element. Results sections need not be very long; they are often the shortest part of the paper. Simply present your results sequentially and concisely. When integrative landscape research is the topic, readers will want to know whether the integrative methodology has led to results that could not have been derived in another way. The results section is the part of the paper that presents the contribution of new knowledge to the existing body of scientific knowledge. We do not recommend combining the presentation of results with their interpretation in one section. Keeping the two parts separate ensures that the reader clearly differentiates results from interpretations. It is helpful to use figures, tables and plates to present the data and findings in this section, but avoid repeating results in the text which are already given in figures or tables.

\section{Discussion}

In this section the reader is informed about the wider meaning and importance of the findings presented in the results section. In the discussion section, the author starts interpreting the data. The discussion section in an integrative research paper is probably the most difficult section to write but is also the most important. It is here that the reader comes to understand the relevance of the findings. The discussion section can often be structured around four topics: (i) the context of the specific findings and potential for generalization; (ii) unexpected results, extreme observations or lacking correlations; (iii) relationship of this study's findings to previous findings in similar or related published research; (iv) theoretical implications of the presented work and its practical application. The discussion section discusses the findings; it does not recapitulate or repeat them. The discussion section relies heavily on a sound state-of-the-art overview (as presented in the introduction).

\section{Conclusion}

In the IMRAD format the conclusion closes the discussion section. We recommend that conclusions be presented in a separate section because they are the third-most frequently read section (after the title and abstract). Furthermore, it is easier for the reader to identify the conclusion when it is separated from the discussion. The conclusion section presents the main conclusions that can be drawn from the presented research. State the conclusions as clearly as possible and make sure they are based on evidence presented in the paper. The conclusion is not a summary section where all parts of the manuscript are repeated.

\section{Acknowledgements}

The purpose of this section is to acknowledge all significant support that the author received in conducting the research and writing the paper. For integrative research papers, it is a section frequently included because authors acknowledge help from other members of the project team or from stakeholders outside academia. Authors might also wish to acknowledge research grants. However, authors are asked to keep the acknowledgements short and limit them to necessary information. The acknowledgement section has no influence on the evaluation of a manuscript and is thus not important for the paper's acceptance or rejection. 


\section{References}

The purpose of the references section is to list all literature that was consulted for the manuscript. With the help of the reference list the reader is able to access all works referred to in the paper. In a peer-reviewed paper, it is important that readers can access the publications to verify the author's arguments and claims. Therefore, the use of publications that cannot be accessed through the international library systems and search databases - i.e. unpublished material, data, abstracts, theses, reports and other secondary material - should be avoided. Wherever possible, a research paper should include mainly English-language literature because publications in other languages cannot be read by most readers. The exception is subject areas where national publications dominate.

Only publications that are actually published or accepted for publication can be taken up in the reference section; in the latter case these publications are referred to as "in press". Submitted manuscripts or papers in review cannot be included in a references section; they can be referred to in other sections as "submitted".

Most journals and books have a specific style for formatting references. Authors are asked to prepare the references sections according to this format prior to first submission. Most formatting and spelling mistakes are made in references sections. Such mistakes can make it impossible for the reader to access the original source material.

\section{Appendix}

The appendix can be used to present additional data that are not critical to understanding the manuscript. An appendix can include an example of a questionnaire or a data table with detailed results that are of interest to the expert. Most papers do not need an appendix.

\section{Ethical considerations}

Authors need to consider ethics when preparing an integrative research paper. In addition to the ethical conflicts that might be related to the research itself, the process of writing and submitting a paper can also raise ethical questions. As a general rule, authors who use the material of others must have permission to use the material and must acknowledge it. For published material it is enough to give full acknowledgment and reference to the original source. For unpublished material, authors must have a written declaration upon submission. The general ethical code of good conduct in publishing does not allow one to use, copy or plagiarize the material of others without full acknowledgment. Disregarding this code may lead to violation of intellectual property rights and copyright, which carries serious legal and disciplinary consequences.

A research paper that is based largely on the material of others - even if fully acknowledged - will be rejected for publication for lack of originality. A piece of research only satisfies the criterion of originality on first publication in a peerreviewed journal. Multiple papers may come from the same project (e.g. a PhD project) but need to be split up in clearly distinguishable pieces. Repetitive publication of the same material is considered poor scientific practice. For more information on ethical aspects of publishing, refer to Serebnick (1991), Day (1998), Luey (2002), Rothwell (2002), Bulger (2004) and Zwart (2004). 


\section{Author guidelines and submission}

Each journal and book publication provides potential authors with manuscript submission guidelines (see journal volumes or journal websites for guidelines). These guidelines include information on the paper's structure but also on the length and format of references, tables and figures. Authors are asked to follow these guidelines strictly because proper formatting will help the editors, referees and publishers speed up the evaluation and publication process. Editors receive many manuscripts and authors cannot expect that good science will be published regardless of a manuscript's formatting. It is most likely that manuscripts not formatted according to the guidelines will be sent back to the authors for reformatting before being further processed or rejected. Thus preparing the manuscript according to the author guidelines saves time and avoids trouble. A useful and detailed guide to manuscript formatting is the handbook on scientific style and format by the Council of Biology Editors (2002).

We strongly recommend giving an advanced draft of the manuscript to experienced colleagues for proofreading and further comments. To improve the style and language of the paper, refer to the classic style guide by Strunk and White (4th ed. 2000). Additionally, we recommend that non-native English speakers give the manuscript to a native speaker or professional language service to correct and refine the language before submission.

Every manuscript submission is accompanied by a cover letter that gives the editor all necessary information on the manuscript and authors (affiliation and contact addresses). Additionally, the cover letter should state that the manuscript is (i) original work carried out by the authors; (ii) has not been published before; (iii) is not being considered for publication elsewhere at the same time; and (iv) all research done by others is fully acknowledged. Violation of any one of these criteria leads to rejection of the manuscript or more serious sanctions.

\section{Editorial and review process}

\section{Role of publisher, editor and referee}

In addition to the authors, three more agents are involved in the preparation and publishing of a paper: the editor, the referees (also called reviewers) and the publisher. While editors and referees are researchers themselves, the publisher is in most cases a commercial enterprise.

The editor mediates between the author, the referees and the publisher. Editors are sometimes considered to be the gatekeepers of science because they decide whether a paper will be published or not. However, editors work in favour of authors, not against them. They are interested in publishing high-quality manuscripts and offer their services to help authors improve their papers. Editors also have the role of safeguarding the quality of their publications. The editor screens and reads incoming manuscripts for their suitability for publication and selects referees. The editor's main tasks are thus quality control of published manuscripts as well as of the editing, reviewing and publishing process. The editor safeguards the fairness of the whole publication process until the paper goes to print. These tasks include all communication with authors, referees and the publishing house. For more information on the role and views of editors, refer to McGinty (1999), Stehbens (1999) and Lampert (2004).

The referees evaluate the scientific quality of a manuscript and suggest further improvements. They are experts in the research field of the paper under review. Their evaluation assists the editor in deciding whether to accept or reject a paper. Referees 
for integrative research papers may come from different subject areas to cover the different disciplinary aspects. Referees may be members of a journal's editorial advisory board or book series or they may be selected based on their expertise in a specific field, evidenced by several peer-reviewed publications of their own. Editors expect referees to give constructive, helpful and insightful comments on the manuscripts. Reviewers need to be open and respectful of the authors' views even when they differ from their own. For more information on the tasks of referees, refer to Forscher (1965) and Smith (1990).

The publisher's involvement starts when a paper is accepted for publication and handed over to the publisher for print. The tasks are not only advertising and marketing of the journal or book where the paper is published, indexing of papers in electronic databases, safeguarding the paper's copyright, but also ensuring that future researchers will have access to the published paper. Since most journal papers are electronically available, guaranteeing access to these electronic files has become a huge challenge for publishing houses because file formats are changing rapidly. Publishers cooperate with libraries and offer search engines and databases for effective and easy access to published material. Finally, the name and reputation of a publishing house influences recognition of a publication.

\section{Peer-review process}

The process of evaluating a manuscript by external and independent experts, peers of the author, is called the peer-review process. The peer-review process is directed and controlled by the editor. The process differs among individual journals and among journals and books. We therefore present the steps in the editorial and review process that are roughly the same for all publication media (see Figure 3). For more details on the discussion about the peer-review process, refer to Dalton (1995), Day (1998), Stehbens (1999), van Rooyen (2001), Weller (2001), Rowland (2002), Hojat et al. (2003), Williamson (2003), Davidoff (2004), Harrison (2004) and Mulligan (2004).

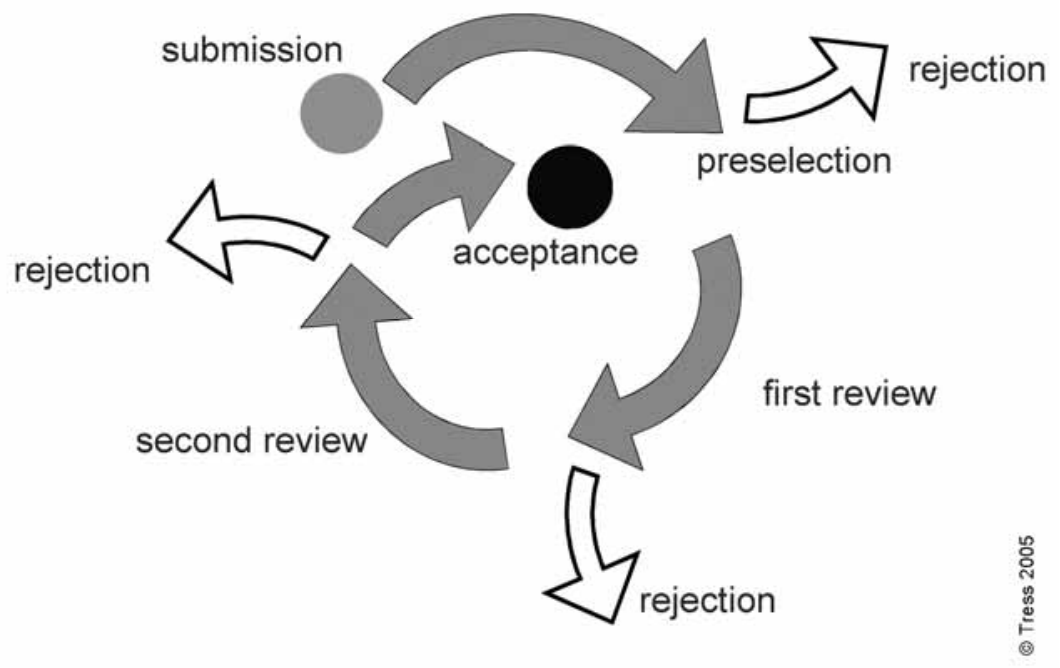

Figure 3. Main steps in the editorial and review process

The first step is the pre-selection in the editorial office. At this stage, the manuscript is screened in the editorial office to determine whether the manuscript fulfils the formal guidelines for manuscript preparation and submission (see 'Author guidelines' section above). If the manuscript meets these requirements it is read and 
the editor decides whether the paper falls within the scope of the journal or book series. Provided the manuscript is within the scope, the editor evaluates whether the manuscript is a new and original contribution, relevant for an international audience, and of sufficient scientific quality to pass the review process and come up to publishing standard. If the manuscript fulfils these criteria it is sent to reviewers. If not, the manuscript is returned to the author or rejected. Usually, about $20 \%$ to $40 \%$ of all manuscripts are rejected at this stage (largely depending on journal and subject area).

Once a manuscript enters the second stage, the first review round, the editor usually selects two or three referees and sends them the manuscript for review. Different types of review processes are applied by journals and book series. Open refereeing means that authors know the names of referees and vice versa. Half-open refereeing means that the referees know the names of authors of papers they review but the authors do not know the names of the referees. Double-blind refereeing keeps the names of authors and referees confidential; only the editorial office knows the names of both parties. In a double-blind review process, manuscripts and review reports are made anonymous. The double-blind review process is the most common. After reviewing the manuscript, referees make a recommendation to the editor as to how to proceed. If it does not need further changes, the reviewer recommends acceptance as it is. If the manuscript needs changes, the reviewer suggests either minor or major revisions. Minor revisions include only small editorial revisions and corrections that might require half a day or a maximum of a few days additional work for the author. Major revisions require substantial changes to the manuscript structure, state-of-the-art overview, data analysis, discussion or other changes that are more time-consuming. Referees may also suggest rejection of the manuscript. Once the referees return the evaluation report to the editorial office, the editor decides what to do next. Papers may be rejected after the first review round but most papers require minor or major revisions and are returned to the authors. Papers are seldom accepted with minor revisions, and acceptance without any further revision is rare.

After the authors revise their manuscript and resubmit it to the editorial office, there is a second review round. For papers that required minor changes, the editor looks at the revised manuscript and assesses whether the requested changes were successfully implemented. If yes, the manuscript may be accepted. If major revisions were requested, the manuscript is sent out to referees again and they re-evaluate the quality of the paper. If necessary, the manuscript is sent back to the authors for another round of minor or major revisions. Usually, no more than two review rounds take place.

The last stage in the process is the editorial decision to accept or reject after the last review and revision round. If the manuscript is now up to publication standard it is accepted. If this is not the case, the manuscript is rejected.

\section{Review criteria}

The review criteria to assess manuscripts in the peer-review process vary from publication to publication. However, we present criteria that are usually applied for publications in the landscape research field, as follows:

- Is the manuscript within the scope of the journal/book series?

- Is it a new and original contribution or has it been published elsewhere?

- Is the author aware of, and does the paper present, an overview of the state of the art for this particular subject?

- Is the title informative and in accordance with the manuscript's content? 
- Is the abstract informative and can it stand alone?

- Are the keywords informative?

- Does the manuscript present a clear statement of objective?

- Are the research methods clearly presented?

- Is the organization of results satisfying?

- Are the interpretations sound?

- Are the conclusions justified by the results presented in the manuscript?

- Is the paper's length appropriate?

- Are the illustrations and tables appropriate and necessary?

- Are references international and complete?

- Is the quality of the English sufficient?

We recommend checking a manuscript against these criteria before submitting it to an editorial office.

\section{What most papers do wrong}

There are many reasons why a manuscript is rejected in the editorial and review process. However, we have identified several problems that appear frequently. Rejection happens when a paper (i) is submitted too early, at a stage when the research is not finished; (ii) does not present clear objectives for the study; (iii) lacks methods, or they are insufficiently explained; (iv) does not clearly indicate its purpose (i.e. review paper, discussion paper, research paper); (v) is of little relevance to an international readership; (vi) does not demonstrate awareness of what has been done internationally in the field; and (vii) is written in sub-standard English. Most of these problems can be addressed before manuscript submission.

\section{Contact between authors, editors and referees}

An important aspect in the editorial and review process is the communication between authors, editors and referees. Refereeing and editing can be regarded as a free service offered by research colleagues. Most do not get paid for it and hardly receive any reimbursements for expenses. The editor and the referees spend many hours of work on each paper. Therefore, it is highly important for authors to make it as easy as possible for editors and referees to do their job. Sticking to the guidelines is rule number one. Being patient is rule number two. Editors and referees aim to handle manuscripts as quickly as possible without being superficial in their judgments. Editors and referees know the importance of a manuscript for an author, but authors need to be aware that editors and referees deal with many manuscripts at the same time. It is helpful for both sides to handle the communication process in a friendly and relaxed manner. This attitude usually characterizes all communication between authors, editors and referees.

\section{Revision process}

Most authors receive their manuscript back from review with a request for revisions. Unfortunately, authors sometimes decide to withdraw their paper from publication at this stage because they feel discouraged when their manuscript needs major revisions. Receiving a request for revision should be seen as an encouraging signal. The paper is of interest to the journal or the book but needs improvement. Editors allow revisions and resubmission within a certain time frame (usually between two and three months), depending on the amount of revision needed. When returning 
the revised manuscript to the editorial office, authors are asked to enclose a detailed letter informing the editor how they have addressed the requested changes. The better the response letter, the easier it is for the editor to make a decision about the revised manuscript. We strongly recommend addressing all comments of the referees and editors in the response letter. The changes requested by referees are no 'wish list' where authors can pick out the suggestions that seem most relevant to them. All requested changes must be addressed in a serious manner even if authors do not agree with a reviewer's comments.

\section{Acceptance and rejection}

A decision about acceptance or rejection is only made at the end of the peer-review process. In almost all cases the decision is final and will not be changed. Rejections are not an evaluation of the author but of the manuscript that has been submitted. Therefore, a rejection should not discourage authors from revising the manuscript or preparing and submitting a new manuscript.

Once a paper has finally been accepted for publication, it is time to celebrate success! The final manuscript will be transferred from the editor's to the publisher's office, and authors will receive proofs before the paper is finally printed.

\section{Concluding recommendations and preparation checklist}

We encourage young researchers and $\mathrm{PhD}$ students involved in integrative landscape research to plan for peer-reviewed publications from their projects. It will help to demonstrate the achievements of integrative landscape research to a broader audience and significantly contribute to the researcher's career development. We recommend using this paper's guidelines when preparing an integrative research paper. In closing, we present a checklist that can be used as a last control before submitting an integrative research paper to an editorial office.

\section{Checklist}

Is/does the manuscript:

a Report on research that is finished?

a Formatted according to guidelines for authors?

a Within the scope of the journal/book series?

- A new and original contribution?

口 Present a relevant issue for an international audience?

- Present and answer a research question?

a Have a clear and easy-to-follow structure?

a Give an overview of the state-of-the-art internationally?

口 Explain the methodology used in the research?

- Explain the integrative character of the research?

a Describe the means of realizing integration in the research project?

口 Been proofread by colleagues and a native English speaker?

口 Acknowledge all research and help derived from others?

If the answers to all these questions are "yes", prepare a submission letter. Authors who have succeeded once in publishing an integrative research paper in a peerreviewed journal or book know that it gets easier every time. 


\section{Acknowledgements}

Thanks to Janine Perron for editing this chapter.

\section{References}

Booth, V., 2003. Communicating in science: writing a scientific paper and speaking at scientific meetings. 2nd edn. Cambridge University Press, Cambridge.

Bruce, A., Lyall, C., Tait, J., et al., 2004. Interdisciplinary integration in Europe: the case of the fifth framework programme. Futures, the Journal of Forecasting Planning and Policy, 36 (4), 457-470.

Bulger, R.E., 2004. The responsible conduct of research, including responsible authorship and publication practices. In: Korthals, M. and Bogers, J. eds. Ethics for life scientists. Springer, Dordrecht, 55-62. Wageningen UR Frontis Series vol. 5. [http://library.wur.nl/frontis/ethics/04a_bulger.pdf]

Council of Biology Editors, 2002. Scientific style and format: the CBE manual for authors, editors, and publishers. 6th edn. Cambridge University Press, Cambridge.

Dalton, M.S., 1995. Refereeing of scholarly works for primary publishing. Annual Review of Information Science and Technology, 30, 213-250.

Davidoff, F., 2004. Improving peer-review: who's responsible? British Medical Journal, 328, 657-658. [http://ebm.vanderbilt.edu/pdf/peer\%20review.pdf]

Day, R.A., 1998. How to write \& publish a scientific paper. 5th edn. University Press, Cambridge. Oorspr. uitg.: Phoenix, AZ: Oryx, 1979

Forscher, B.K., 1965. Rules for referees. Science, 150 (3694), 319-321.

Fry, G., Tress, B. and Tress, G., 2004. The potential and limitations of integrated grassland research. In: Lüscher, A., Jeangros, B., Kessler, W., et al. eds. Land use systems in grassland dominated regions: proceedings of the 20th general meeting of the European Grassland Federation, Luzern, Switzerland, 21-24 June 2004. vdf Hochschulverlag AG an der ETH Zürich, Zürich, 1157-1167. Grassland Science in Europe no. 9.

Fry, G., Tress, B. and Tress, G., 2005. PhD students and integrative research. In: Tress, B., Tress, G., Fry, G., et al. eds. From landscape research to landscape planning: aspects of integration, education, and application. Springer, Dordrecht, this volume, chapter 14. Wageningen UR Frontis Series vol. 12. [http://library.wur.nl/frontis/landscape_research/14_fry.pdf]

Fry, G.L.A., 2001. Multifunctional landscapes: towards transdisciplinary research. Landscape and Urban Planning, 57 (3/4), 159-168.

Gustavii, B., 2003. How to write and illustrate a scientific paper. Cambridge University Press, Cambridge.

Harrison, C., 2004. Peer review, politics and pluralism. Environmental Science \& Policy, 7 (5), 357-368.

Hojat, M., Gonnella, J.S. and Caelleigh, A.S., 2003. Impartial judgement by the "gatekeepers" of science: fallibility and accountability in the peer review process. Advances in Health Sciences Education, 8 (1), 75-96.

Jakobsen, C.-H., Hels, T. and McLaughlin, W.-J., 2004. Barriers and facilitators to integration among scientists in transdisciplinary landscape analyses: a crosscountry comparison. Forest Policy and Economics, 6 (1), 15-31. 
Lampert, C., 2004. Being the editor-in-chief of a primary research journal: an editor's opinion. Elsevier. [http://www.elsevier.com/framework_editors/pdfs/ Editorsguide.pdf]

Luey, B., 2002. Handbook for academic authors. 4th edn. Cambridge University Press, Cambridge.

McGinty, S., 1999. Gatekeepers of knowledge: journal editors in the sciences and the social sciences. Bergin \& Garvey, Westport.

Mulligan, A., 2004. Is peer review in crisis? Elsevier. Elsevier's Perspectives in Publishing 2. [http://www.elsevier.com/framework_editors/pdfs/PerspPubl2. pdf]

Provost, G., 1985. 100 ways to improve your writing. Mentor Books, New York.

Rothwell, N., 2002. Who wants to be a scientist? Choosing science as a career. Cambridge University Press, Cambridge.

Rowland, F., 2002. The peer-review process. Learned Publishing, 15 (4), 247-258.

Serebnick, J., 1991. Identifying unethical practices in journal publishing. Library Trends, 40 (2), 357-372.

Smith, A.J., 1990. The task of the referee. IEEE Computer, 23 (4), 65-73. [http://www.idt.mdh.se/phd/Smith-TaskOfTheReferee.pdf]

Spanner, D., 2001. Border crossings: understanding the cultural and informational dilemmas of interdisciplinary scholars. The Journal of Academic Librarianship, 27 (5), 352-360.

Stehbens, W.E., 1999. Basic philosophy and concepts underlying scientific peer review. Medical Hypotheses, 52 (1), 31-36.

Strunk, W. and White, E.B., 2000. The elements of style. 4th edn. Allyn and Bacon, Boston.

Tress, B., Tress, G. and Fry, G., 2005. Integrative studies on rural landscapes: policy expectations and research practice. Landscape and Urban Planning, 70 (1/2), 177-191.

Tress, G., Tress, B. and Fry, G., in press. Clarifying integrative research concepts in landscape ecology. Landscape Ecology.

Tress, G., Tress, B., Fry, G., et al., 2005. Trends in landscape research and landscape planning: implications for PhD students. In: Tress, B., Tress, G., Fry, G., et al. eds. From landscape research to landscape planning: aspects of integration, education, and application. Springer, Dordrecht, this volume, chapter 1. Wageningen UR Frontis Series vol. 12. [http://library.wur.nl/frontis/ landscape_research/01_introduction.pdf]

Van der Sanden, M.C.A. and Meijman, F.J., 2004. Evidence-based science communication. Science Communication, 25 (3), 272-287.

Van Rooyen, S., 2001. The evaluation of peer-review quality. Learned Publishing, 14 (2), 85-91.

Weller, A., 2001. Editorial peer review: its strength and weaknesses. Information Today, Medford. Asis\&T Monograph Series.

Williamson, A., 2003. What will happen to peer review? Learned Publishing, 16 (1), 15-20.

Zwart, H., 2004. Professional ethics and scholarly communication. In: Korthals, M. and Bogers, R.J. eds. Ethics for life scientists. Springer, Dordrecht, 67-80. Wageningen UR Frontis Series vol. 5. [http://library.wur.nl/frontis/ethics/ 05a_zwart.pdf] 